\title{
Study on the Response of PM2.5 Pollution to Land Use Change Based on GIS
}

\author{
Ping Zhang ${ }^{1, a}$, Liang $\mathrm{He}^{2, \mathrm{~b}}$, Yajuan Zhou ${ }^{3, \mathrm{c}}$, Peishu Huo ${ }^{4, \mathrm{~d}^{*}}$ and Wenbiao \\ $\operatorname{Tian}^{1, e}$
}

${ }^{1}$ School of Environmental and Chemical Engineering, Xi an Polytechnic University, Xi an 710048, China

${ }^{2} X i$ 'an Environmental Monitoring Station, Xi'an 710054, China

${ }^{3}$ College of Territorial Resources and Tourism, Anhui Normal University, Wuhu 241002, China

${ }^{4}$ China Construction Water and Environment Protection Co. Ltd, Beijing 100193, China

amiracle1891@126.com, ${ }^{\mathrm{b}}$ he121@163.com, 'cnmiracle2008@126.com, dangelback2005@126.com, ${ }^{\mathrm{e}}$ mirage3000@163.com

*The corresponding author

Keywords: Geographic Information System; PM2.5; Land use; Change; Response

\begin{abstract}
PM2.5 pollution is harmful to human health and ecological environment, and effective control of PM2.5 pollution has important practical significance for regional sustainable development. This paper analyzed the impact of land use change on PM2.5 pollution based on Geographic Information System (GIS), the results showed that: Xi'an has the largest arable land, accounted for $37 \%$ of the total area, followed by forest cover with $32 \%$, grass land and construction land accounted for $15 \%$, respectively, and water bodies and unused land accounted for $0.01 \%$, respectively. The seasonal order of PM2.5 pollution in Xi'an in 2014 was: winter> spring> autumn> summer. The highest concentration of PM2.5 in winter is $151-198 \mathrm{ug} / \mathrm{m} 3$, the high pollution area is mainly distributed in the south-central and north-central, the middle pollution zone is mainly in the west and the east, the low pollution area is mainly distributed in the central and northeast. There was a significant negative correlation between PM2.5 concentration and water bodies in summer, the correlation coefficient was -0.601 . However, PM2.5 concentration was positively correlated with arable land in autumn, the correlation coefficient was 0.603 . The results could provide the scientific basis for prevention and control of PM2.5 pollution.
\end{abstract}

\section{Introduction}

Atmospheric particulate matter (PM2.5) is one of the most important air pollutants [1, 2]. It is also the primary pollutant which affects the air quality of most cities in China. The impact of airborne particulate pollution on health has become the focus of public and governments. Land use and land-cover change (LUCC) directly or indirectly affect particulate pollution [3]. Revealing the law of the response of particulate pollution to land use change has great significance for maintain and improve the ecological environment [4-6].

At present, the domestic and foreign researchers mainly pay attention to the influence of land use on the spatial distribution of air quality [7-10], but mostly focus on the individual factors such as vegetation coverage index, and discuss the impact of land use type change on air quality at annual scale. However, the relationship between Land use and land-cover change and air quality at the annual scale is also often obscured by seasonal factors such as weather. In addition, most of the studies used time series analysis, the study of space-time scale is stills less.

In summary, the Geographic Information System (GIS) in this paper was used to obtain the land use data of the study area, and analyzes the spatial distribution characteristics of season and average PM2.5 pollution and the land use type, quantitatively evaluates the correlation between PM2.5 and land use change. The results provide scientific basis for revealing the relationship between land use 
change and atmospheric particulate pollution and the rational exploitation and utilization of urban land.

\section{Materials and Methods}

PM2.5 Concentration Data Acquisition. The air pollution data used in this study were collected from the Xi'an environmental monitoring station, including 13 air quality monitoring points, and obtained the daily PM2.5 concentration monitoring data in 2014.

Land Use Remote Sensing Data Obtain. The research data include land use data in Xi an in 2014, which were 1:100,000 Landsat TM remote sensing imagery interpretation data. Combined with actual conditions of study area and needs of this paper, land use types in Xi an in were divided into grassland, water bodies, arable land, forest cover, construction land and unused land.

Pretreatment of PM2.5 Concentration Data. The study area is divided into four seasons: March-May is spring, June-August is summer, September-November is autumn, December and January-February are winter. The concentrations of PM2.5 in different seasons were calculated.

\section{Results and Analysis}

Analysis of Land Use Structure in Xi'an in 2014. Based on GIS, the land use data of Xi'an in 2014 were mapped and analyzed, as shown in Fig. 1.

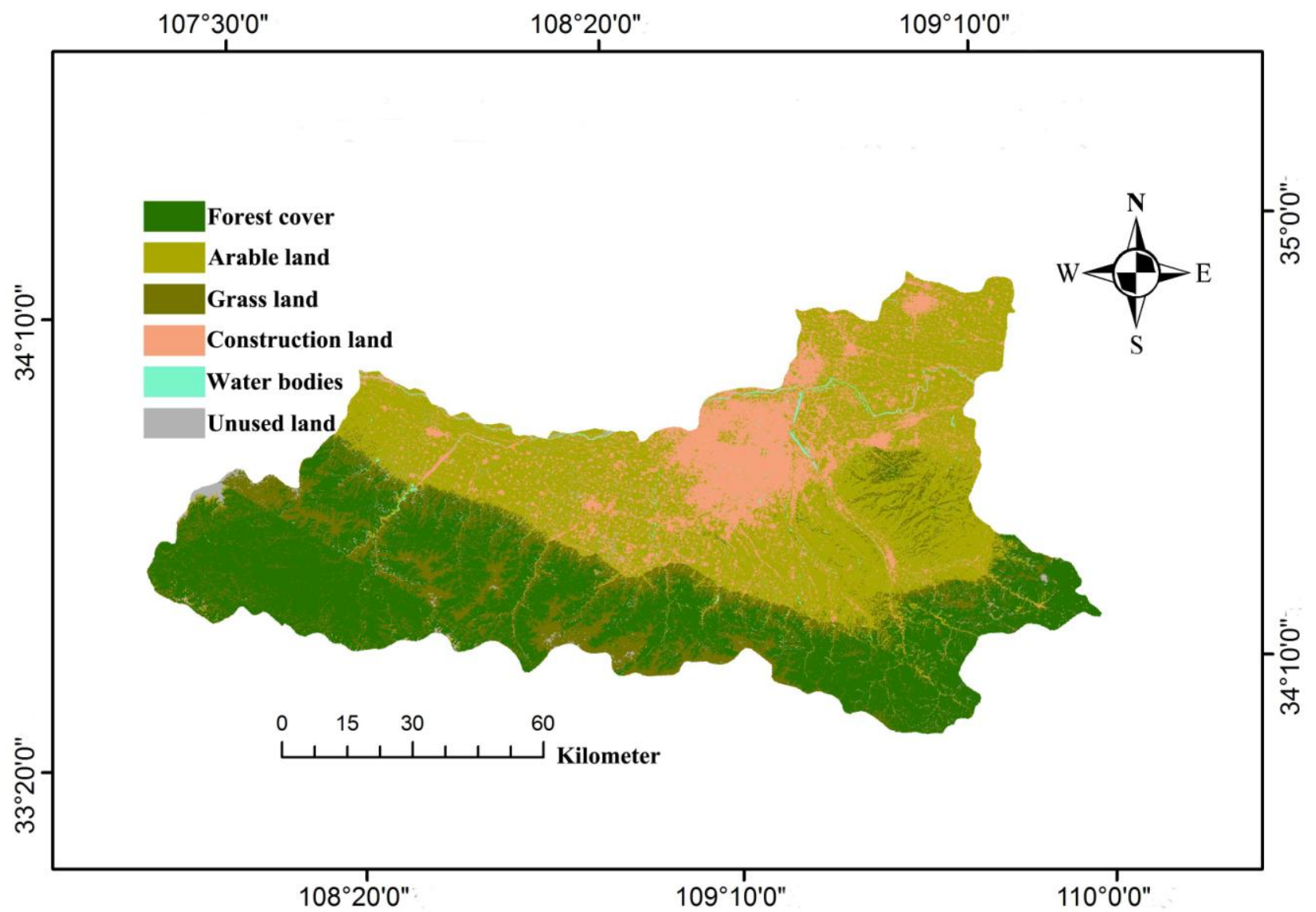

Figure 1. Spatial distribution of land use in Xi'an in 2014

As shown in Fig. $1 \mathrm{Xi}$ 'an has the largest arable land, accounted for $37 \%$ of the total area, followed by forest cover with $32 \%$, grass land and construction land accounted for $15 \%$, respectively, and water bodies and unused land accounted for $0.01 \%$, respectively. The results showed that the area of different types of land use in Xi'an from high to low in the order of: arable land $>$ forest cover $>$ construction land $>$ grass land $>$ water bodies $>$ unused land. 
Fig. 2 shows that the seasonal order of PM2.5 pollution in Xi'an in 2014 is: winter> spring> autumn> summer. The concentration of PM2.5 in winter is $151-198 \mathrm{ug} / \mathrm{m} 3$. The high pollution area is mainly distributed in the south-central and north-central, the middle pollution area is mainly in the west and the east, the low pollution area is mainly distributed in the middle and northeast. The PM2.5 concentration in spring is $79-124 \mathrm{ug} / \mathrm{m} 3$. The high pollution area is mainly distributed in the north-central and south-central regions, the middle-polluted areas are mainly distributed in the west and southeast, and the low pollution areas are mainly in the middle and northeast. The concentration of PM2.5 in autumn was $69-81 \mathrm{ug} / \mathrm{m} 3$. The high pollution areas were mainly distributed in the northeast and the central and southern regions, the middle polluted areas were mainly distributed in the west and southeast, and the low pollution areas were mainly distributed in the central. The concentration of PM2.5 in the summer is $56-60 \mathrm{ug} / \mathrm{m} 3$. The high pollution area is mainly distributed in the northeast and central area. The middle pollution area mainly distributed in the west and southeast, and the low pollution area is mainly in the south central and north central. However, the average annual PM2.5 concentration is $92-112 \mathrm{ug} / \mathrm{m} 3$, the high pollution areas are mainly distributed in the north and south-central, the middle polluted areas are mainly distributed in the northwest and southeast, low-pollution areas are mainly distributed in the central.

Relationship between PM2.5 Pollution and Land Use Type. The relationship between PM2.5 concentration and land use types in different seasons was quantitatively analyzed by SPSS. The results are shown in the following table (Table 1).

Table 1 Correlation between $\mathrm{PM}_{2.5}$ concentration and land use type in different seasons in $\mathrm{Xi}$ an in 2014

\begin{tabular}{ccccc} 
& \multicolumn{4}{c}{$\mathrm{PM}_{2.5}$ pollution } \\
\cline { 2 - 5 } & Spring & Summer & Autumn & Winter \\
\hline Forest cover & -0.114 & -0.009 & -0.428 & -0.021 \\
Arable land & -0.295 & 0.175 & $0.603^{*}$ & -0.102 \\
Grass land & -0.120 & -0.001 & -0.411 & -0.019 \\
Construction land & 0.068 & -0.114 & 0.248 & 0.215 \\
Water bodies & -0.213 & $-.601^{*}$ & -0.142 & 0.172 \\
Unused land & -0.203 & 0.128 & -0.243 & -0.217 \\
\hline
\end{tabular}

* Significance at the 0.05 probability level.

As shown in Table 1, in general, forest cover, grass land, water bodies and unused land had negative correlation with PM2.5 concentration, and had different degree of control and abatement on PM2.5 pollution. In contrast, there was a positive correlation between PM2.5 concentration and construction land and arable land, and had different contribution to PM2.5 pollution. There was a significant negative correlation between PM2.5 concentration and water bodies in summer, the correlation coefficient was -0.601 . However, PM2.5 concentration was positively correlated with arable land in autumn, the correlation coefficient was 0.603 .

In spring, the correlation coefficients of PM2.5 concentration with forest cover, arable land, grass land, construction land, water bodies and unused were $-0.114,-0.295,-0.120,0.068,-0.213$ and -0.203 , respectively. In summer, the correlation coefficients of PM2.5 concentration with forest cover, arable land, grass land, construction land, water bodies and unused were $-0.009,0.175$, $-0.001,-0.114,-0.601$ and 0.128 , respectively. In autumn, the correlation coefficients of PM2.5 concentration with forest cover, arable land, grass land, construction land, water bodies and unused land were $-0.428,0.603,-0.411,0.248,-0.142$ and -0.243 , respectively. In winter, the correlation coefficient of PM2.5 concentration with forest cover, arable land, grass land, construction land, water bodies and unused land were $-0.021,-0.102,-0.019,0.215,0.172$ and -0.217 , respectively. 


\section{Summary}

This paper researched the response of PM2.5 pollution to land use change by using GIS, the results showed that:

(1) The area of different types of land use in Xi'an from high to low in the order of: arable land> forest cover $>$ construction land $>$ grass land $>$ water bodies $>$ unused land. Xi'an has the largest arable land, accounted for $37 \%$ of the total area, followed by forest cover with $32 \%$, grass land and construction land accounted for $15 \%$, respectively.

(2) The seasonal order of PM2.5 in Xi'an in 2014 is: winter> spring> autumn> summer. The concentration of PM2.5 in winter, spring, autumn, summer and average annual were 151-198 $\mathrm{ug} / \mathrm{m} 3,79-124 \mathrm{ug} / \mathrm{m} 3,69-81 \mathrm{ug} / \mathrm{m} 3,56-60 \mathrm{ug} / \mathrm{m} 3$ and $92-112 \mathrm{ug} / \mathrm{m} 3$

(3) Forest cover, grass land, water bodies and unused land had negative correlation with PM2.5 concentration, and had different degree of control and abatement on PM2.5 pollution. In contrast, there was a positive correlation between PM2.5 concentration and construction land and arable land, and had different contribution to PM2.5 pollution. In spring, the correlation coefficients of PM2.5 concentration with forest cover, arable land, grass land, construction land, water bodies and unused were $-0.114,-0.295,-0.120,0.068,-0.213$ and -0.203 , respectively. However, In winter, the correlation coefficient of PM2.5 concentration with forest cover, arable land, grass land, construction land, water bodies and unused land were $-0.021,-0.102,-0.019,0.215,0.172$ and -0.217 , respectively.

\section{Acknowledgements}

This research was supported by funding by the Scientific Research Program Funded by Shaanxi Provincial Education Department (Program No. 2015JK1329, 2017JK), the PhD research start-up foundation of Xi'an Polytechnic University (No. BS1306), students' innovation and entrepreneurship training foundation at the provincial level of Xi'an Polytechnic University (No. 1720).

\section{Reference}

[1] Y. Wang, C. Jia, J. Tao, L. Zhang, X. Liang, J. Ma, G. Hong, H. Tao and Z. Kai, Chemical characterization and source apportionment of PM2.5 in a semi-arid and petrochemical-industrialized city, Northwest China, Science of the Total Environment. 573 (2016) 1031-1040.

[2] S. Steinle, S. Reis, C.E. Sabel, S. Semple, M.M. Twigg, C.F. Braban, S.R. Leeson, M.R. Heal, D. Harrison and C. Lin, Personal exposure monitoring of PM2.5 in indoor and outdoor microenvironments, Science of the Total Environment. 508 (2015) 383-394.

[3] L.M.I. Canals and L.D. Baan, Land Use, Springer Netherlands, Netherland, 2015.

[4] W. Yuchi, A. Knudby, J. Cowper, E. Gombojav, O. Amram, B.B. Walker and R.W. Allen, A description of methods for deriving air pollution land use regression model predictor variables from remote sensing data in Ulaanbaatar, Mongolia, Canadian Geographer. 60 (2016) 333-345.

[5] A. Aziz and G.A. Anjum, Sensitizing Land Uses to Control Motor Vehicular Air Pollution: a Case Study of Lahore in Connection with Paris, Environmental Modeling \& Assessment. 21 (2016) 1-17.

[6] S. Hankey and J.D. Marshall, Land Use Regression Models of On-Road Particulate Air Pollution (Particle Number, Black Carbon, PM2.5, Particle Size) Using Mobile Monitoring, Environmental Science \& Technology. 49 (2015) 9194-9202.

[7] L. Sun, J. Wei, D.H. Duan, Y.M. Guo, D.X. Yang, C. Jia and X.T. Mi, Impact of Land-Use and Land-Cover Change on urban air quality in representative cities of China, Journal of Atmospheric and Solar-Terrestrial Physics. 142 (2016) 43-54. 
[8] D.R. Michanowicz, J.L.C. Shmool, L. Cambal, B.J. Tunno, S. Gillooly, M.J.O. Hunt, S. Tripathy, K.N. Shields and J.E. Clougherty, A hybrid land use regression/line-source dispersion model for predicting intra-urban NO 2, Transportation Research Part D Transport \& Environment. 43 (2016) 181-191.

[9] A. Marcon, K. De Hoogh, J. Gulliver, R. Beelen and A.L. Hansell, Development and transferability of a nitrogen dioxide land use regression model within the Veneto region of Italy, Atmospheric Environment. 122 (2015) 696-704.

[10] M. Eeftens, R. Meier, C. Schindler, I. Aguilera, H. Phuleria, A. Ineichen, M. Davey, R. Ducret-Stich, D. Keidel and N. Probst-Hensch, Development of land use regression models for nitrogen dioxide, ultrafine particles, lung deposited surface area, and four other markers of particulate matter pollution in the Swiss SAPALDIA regions, Environmental Health. 15 (2016) $1-14$. 